\title{
Cardiovascular risk assessment according to the Framingham score and abdominal obesity in individuals seen by a clinical school of nutrition
}

\author{
Alane Cabral Menezes de Oliveira ${ }^{1 *}$, Raphaela Costa Ferreira $^{2}$, Arianne Albuquerque Santos $^{3}$ \\ ${ }^{1}$ Adjunct Professor of Nutrition, Universidade Federal de Alagoas. PhD in Biotechnology Applied to Health, Maceió, AL, Brazil \\ ${ }^{2}$ Nutrition MSc Student, Faculdade de Nutrição, Universidade Federal de Alagoas, Maceió, AL, Brazil \\ ${ }^{3}$ Multidisciplinary Resident (Physician), Hospital Universitário Prof. Alberto Antunes, Maceió, AL, Brazi
}

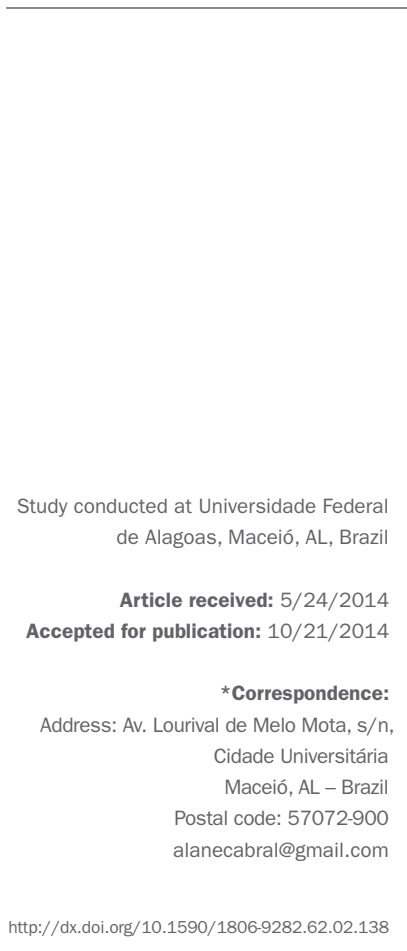

\section{SUMMARY}

Objective: To analyze the relation of abdominal obesity on cardiovascular risk in individuals seen by a clinic school of nutrition, classifying them based on Framingham score.

Methods: Cross-sectional study, conducted at the nutrition clinic of a private college in the city of Maceió, Alagoas. We included randomly selected adults and elderly individuals with abdominal obesity, of both sexes, treated from August to December of 2009, with no history of cardiomyopathy or cardiovascular events. To determine the cardiovascular risk, the Framingham score was calculated. All analyzes were performed with SPSS software version 20.0 , with $\mathrm{p}<0.05$ as significative.

Results: We studied 54 subjects, $83 \%$ female, the mean age was 48 years old, ranging from 31 to 73 years. No correlation was observed between measurements of waist circumference and cardiovascular risk in the subjects studied $(\mathrm{r}=0.065$, $\mathrm{p}=0.048$ ), and there was no relationship between these parameters.

Conclusion: Abdominal fat distribution was weakly related to cardiovascular risk in patients seen by a clinical school of nutrition.

Keywords: Abdominal obesity, cardiovascular diseases, obesity, risk factors.

\section{INTRODUCTION}

Cardiovascular diseases (CVD) are the leading causes of death in women and men in Brazil. They are responsible for about $20 \%$ of all deaths in individuals aged over 30 years, indicating their importance as a public health problem, as well as showing the close relationship with the level of obesity of the population. ${ }^{1}$

Obesity in modern and globalized society has spread to alarming levels in all age groups. It is a chronic disease, resulting from the chronic imbalance between food intake and energy expenditure. It is highly complex, has a multifactorial etiology, with biological, psychological, social and economic variables that also involve environmental and genetic aspects, and is difficult to treat, with high morbidity and mortality. Its risk increases progressively in accordance with weight gain, associated with a series of factors such as dyslipidemia, hypertension (SAH), diabetes mellitus (DM) and insulin resistance, factors that can also increase cardiovascular risk. ${ }^{2,3}$
In recent years, adipose tissue has become more than just energy reserve being recognized as an organ with multiple functions and a central role in the genesis of insulin resistance. Currently, it is known that adipocytes receive the influence of various signals such as insulin, cortisol and catecholamines and, in response, secrete a wide variety of substances (leptin, adiponectin, TNF- $\alpha$ [tumor necrosis factor alpha] and more), which act both locally and systemically, participating in the regulation of various processes such as endothelial function, atherogenesis, insulin sensitivity and regulation of the energy balance. It is also recognized that, depending on their location, adipocytes present different metabolic features, and intra-abdominal adiposity presents the greatest impact on the deterioration of insulin sensitivity. ${ }^{4}$

For the diagnosis of obesity, there are several indirect methods that allow us a precise estimate of the amount of body fat, as well as its distribution. Among these methods we can highlight computed tomography, dual ener- 
gy X-ray absorptiometry (DEXA) and magnetic resonance imaging (MRI). For epidemiological studies, however, considering the simplicity and the costs of various methods, the use of anthropometric indexes has been recommended: BMI, waist-hip ratio (WHR) or simply waist circumference (WC). ${ }^{5}$

The anthropometric methods proposed to analyze the distribution of body fat include skinfolds, waist-hip ratio and waist circumference (WC), the latter being one of the methods most commonly used in the literature to assess abdominal adiposity, with suggested cut-off points associated with increased cardiovascular risk. ${ }^{6,7}$

As for the cardiovascular risk, it can be measured using the Framingham risk scale, created according to a prospective observational study carried out in a small town in the northeast of the United States of America (USA). This study evaluated blood pressure, smoking, lipid profile and other characteristics of 5,300 individuals from different ethnic groups and resident in Framingham, aged between 30 and 74 years, as well as the causes of death and disease over a period of 50 years. Lastly, the results of this study were used to calculate the absolute risk of coronary events, both fatal and non-fatal, over the next 10 years. ${ }^{8}$

As such, the present study aimed to evaluate the relationship between central body fat distribution and cardiovascular risk, according to the Framingham score, in individuals with abdominal obesity seen at a clinical school of nutrition, so as to direct health action strategies for reducing the incidence of cardiovascular events.

\section{Methods}

This research is part of a larger study entitled "Anthropometric marker of abdominal obesity: a screening instrument for high cardiovascular risk?" conducted at the Clinical School of Nutrition at the Centro de Estudos Superiores de Maceió (CESMAC), located in the city of Maceió (AL), in the period from August to December 2009.

This is a cross-sectional study type study, conducted with a randomly selected sample, which included adults with abdominal obesity, older than 30 years, and elderly of both sexes, with no history of cardiomyopathies and cardiovascular events. The research excluded all children, adolescents, pregnant women and adults under the age of 30 years seen by the clinical school of nutrition.

To assess the nutritional status of the participants in the study the following data was collected: (1) weight and height measurements to calculate body mass index (BMI) obtained from formula $=$ weight $/$ height ${ }^{2}\left(\mathrm{Kg} / \mathrm{m}^{2}\right)$ using the cut-off points established by the World Health Organization (WHO, 1995); ${ }^{9}$ (2) estimated percentage of body fat obtained by the sum of the four skin folds (biceps, triceps, subscapular and suprailiac), taken using an nonelastic measuring tape and Lange ${ }^{\circledast}$ type calipers, estimated based on Durnin and Womersley $(1974)^{10}$ and classified following the reference values for body fat percentages according to gender, and (3) measurement of the waist circumference (WC) for confirmation of the diagnosis of abdominal obesity, using a non-elastic tape measure and measured at the midpoint between the iliac crest and the external surface of the last rib, using the cut-off points established by the International Diabetes Federation (IDF), ${ }^{11}$ where a normal WC would be $\leq 90 \mathrm{~cm}$ for men and $\leq 80 \mathrm{~cm}$ for women, respectively.

To determine the cardiovascular risk, the Framingham score was calculated, ${ }^{8}$ which takes into consideration the following factors: age; gender; presence or absence of type $2 \mathrm{DM}$; smoking (consumption of any number of cigarettes in the last 30 days); high-density lipoproteins cholesterol (HDL-c) and total cholesterol values; as well as blood pressure values. Each of these factors is assigned a pre-established value, later added to the others. The result is a final value that is correlated with a table of percentage risks for developing CVD within ten years.

To do this, a standardized questionnaire containing information about age, sex, presence or absence of DM, smoking, alcoholism, physical inactivity and family history of CVD was first applied.

The biochemical variables (total cholesterol, triglycerides, low-density lipoprotein cholesterol (LDL-c), HDL-c and fasting glucose) were measured in laboratory using standardized and routine methods, through the collection of venous blood after fasting for 12 hours. For dyslipidemia, the following cut-off points were considered: total cholesterol: $\geq 200 \mathrm{mg} / \mathrm{dL}$; triglycerides: $\geq 150 \mathrm{mg} / \mathrm{dL}$; HDL $<40 \mathrm{mg} / \mathrm{dL} ; \mathrm{LDL} \geq 130 \mathrm{mg} / \mathrm{dL} .{ }^{12}$ For abnormal fasting glycemia levels, we used fasting glycemia $>100 \mathrm{mg} / \mathrm{dL} .{ }^{13}$

Systemic blood pressure measurements were obtained by evaluating the systolic blood pressure (SBP) and diastolic blood pressure (DBP). The cut-off points used were $130 \mathrm{mmHg}$ for SBP and $85 \mathrm{mmHg}$ for DBP. ${ }^{14}$

All analyses were carried out with the aid of the Microcal software SPSS (Statistical Package for Social Science) version 20.0, adopting a confidence interval of $95 \%$ $(\mathrm{p}=0.05)$. For comparison of frequencies and averages we used the chi-square test, Fisher's exact test and Student's $t$ test, respectively. Pearson correlation coefficient was used to assess the correlation. 
The present study was approved by the Research Ethics Committee of the CESMAC University Center under protocol number 679-9.

\section{Results}

54 individuals were studied from a total of 83 seen during the study period, 45 (83\%) of whom were female and $9(17 \%)$ male. When classified by age group: 41 adults (79.9\%), and 13 elderly individuals (20.1\%), with an average age of 48 years, ranging from 31 to 73 years.

The anthropometric and biochemical variables and lifestyle of the individuals under study are displayed in Table 1 . Thus, there was no significant difference $(p>0.05)$ for these variables when compared between age group (adults and the elderly) and sex, which shows the homogeneity of the sample. The highest frequencies found for the adult population were those pertaining to: excess weight (BMI); excess adipose tissue (according to the sum of the skin folds); physical inactivity and family history of CVD. For the elderly, in addition to the anthropometric indicators of obesity, hypertension was also relevant, as it was present in 10 of the 13 elderly individuals.

Table 2 presents the average standard deviation of the anthropometric and biochemical variables of the individuals studied according to age group and sex. When evalu- ated by sex and age group, women showed a higher frequency of obesity according to the sum of the skin folds $(p<0.05)$. For the other parameters studied, there was no significant difference. The averages of the biochemical variables of the individuals under study were: total cholesterol $206.65 \pm 44.78 \mathrm{mg} / \mathrm{dL}$; HDL-c $58.43 \pm 12.77 \mathrm{mg} / \mathrm{dL}$; LDL-c $123.794 \pm 40.67 \mathrm{mg} / \mathrm{dL}$, triglyceride $128.11 \pm 37.46$ $\mathrm{mg} / \mathrm{dL}$ and fasting glucose $93.15 \pm 15.78 \mathrm{mg} / \mathrm{dL}$.

According to Table 3, it is possible to observe that $91 \%$ of the individuals assessed were classified as low risk $(78 \%$ male and $93 \%$ female); $7.4 \%$ as medium risk (22\% male versus $5.0 \%$ female) and $2 \%$ as high risk, present only in the female sex, of developing cardiovascular disease within 10 years. The only significant differences between men and women $(p \leq 0.05)$ was in the relative frequency of the low cardiovascular risk, where the women in the study showed a lower risk of developing cardiovascular disease within 10 years when compared with men. Furthermore, in general, increasing age is not related with an increase in the overall cardiovascular risk in this population, and cardiovascular events are happening earlier and earlier.

Lastly, there was an almost zero correlation between waist circumference measurements and cardiovascular risk of the individuals studied ( $r=0.065$; $\mathrm{p}=0.048)$, therefore there is no relationship between these parameters.

TABLE 1 Distribution of individuals with abdominal obesity according to anthropometric, biochemical, clinical and lifestyle variables, Maceió (AL), 2009.

\begin{tabular}{|c|c|c|c|c|c|c|c|c|}
\hline \multirow[b]{2}{*}{ Variables } & \multicolumn{4}{|c|}{ Adults ( $<60$ years) } & \multicolumn{4}{|c|}{ Elderly (> 60 years) } \\
\hline & $\begin{array}{l}\text { Female } \\
(n=35)\end{array}$ & $\begin{array}{l}\text { Male } \\
(n=6)\end{array}$ & $\begin{array}{l}\text { Total } \\
(n=41)\end{array}$ & $\mathbf{P}^{* * * *}$ & $\begin{array}{l}\text { Female } \\
(n=10)\end{array}$ & $\begin{array}{l}\text { Male } \\
(n=3)\end{array}$ & $\begin{array}{l}\text { Total } \\
(n=13)\end{array}$ & $\mathbf{p}^{* * * *}$ \\
\hline & n (\%) & n (\%) & n (\%) & & n (\%) & n (\%) & n (\%) & \\
\hline Excess weight * & $29(82.85)$ & $5(83.33)$ & $34(82.92)$ & 0.7322 & $7(70.00)$ & $2(66.66)$ & $9(69.23)$ & 0.7062 \\
\hline Excess fat tissue $e^{* *}$ & $27(77.14)$ & $4(66.66)$ & $31(75.60)$ & 0.4583 & $7(70.00)$ & $3(100.00)$ & $10(76.92)$ & 0.4195 \\
\hline Fasting hyperglycemia & $7(20.00)$ & $0(0)$ & $7(17.07)$ & 0.2991 & $3(30.00)$ & $2(66.66)$ & $5(38.46)$ & 0.3146 \\
\hline Elevated serum triglyceride & $12(34.28)$ & $2(33.33)$ & $14(34.14)$ & 0.6723 & $2(20.00)$ & $1(33.33)$ & $3(23.07)$ & 0.5804 \\
\hline Elevated serum cholesterol & $17(45.57)$ & $3(50.00)$ & $20(48.78)$ & 0.6445 & $7(70.00)$ & $1(33.33)$ & $8(61.53)$ & 0.3146 \\
\hline Elevated serum LDL-c & $11(31.42)$ & $2(33.33)$ & $13(31.70)$ & 0.6320 & $4(40.00)$ & $1(33.33)$ & $5(38.46)$ & 0.6853 \\
\hline Low serum HDL-c & $15(42.85)$ & $1(16.66)$ & $16(39.02)$ & 0.2284 & $0(0)$ & $0(0)$ & $0(0)$ & ----- \\
\hline Dyslipidemia $* * *$ & $6(17.14)$ & $1(16.66)$ & $7(17.07)$ & 0.7322 & $1(10.00)$ & $0(0)$ & $1(7.69)$ & 0.7292 \\
\hline Diabetes mellitus *** & $2(5.71)$ & $0(0)$ & $2(4.87)$ & 0.7256 & $1(10.00)$ & $1(33.33)$ & $2(15.38)$ & 0.4230 \\
\hline $\begin{array}{l}\text { Arterial high blood } \\
\text { pressure }^{* * *}\end{array}$ & $12(34.28)$ & $1(16.66)$ & $13(37.14)$ & 0.3679 & $7(70.00)$ & $3(100.00)$ & $10(76.92)$ & 0.4195 \\
\hline Drinking habit & $11(31.42)$ & $3(50.00)$ & $14(34.14)$ & 0.3276 & $1(10.00)$ & $1(33.33)$ & $2(15.38)$ & 0.4230 \\
\hline Physical inactivity & $25(71.42)$ & $4(66.66)$ & $29(70.73)$ & 0.5774 & $2(20.00)$ & $1(33.33)$ & $3(23.07)$ & 0.5804 \\
\hline Smoking habit & $0(0)$ & $0(0)$ & $0(0)$ & ----- & $1(10.00)$ & $1(33.33)$ & $2(15.38)$ & 0.4230 \\
\hline Family history of CVD & $24(68.57)$ & $5(83.33)$ & $29(70.73)$ & 0.4225 & $6(60.00)$ & $1(33.33)$ & $7(53.84)$ & 0.4370 \\
\hline
\end{tabular}

${ }^{*}$ Excess weight according to the IMC; ${ }^{* *}$ Excess adipose tissue according to the sum of skin folds; ${ }^{* * *}$ Medical diagnosis; ${ }^{* * * *}$ Chi-square test, Fisher's exact test. 
TABLE 2 Average standard deviations of anthropometric and biochemical variables in individuals with abdominal obesity according to age group and sex, Maceió (AL), 2009.

\begin{tabular}{|c|c|c|c|c|c|c|}
\hline \multirow[b]{2}{*}{ Variables } & \multicolumn{3}{|c|}{ Adults (< 60 years) } & \multicolumn{3}{|c|}{ Elderly (> 60 years) } \\
\hline & $\begin{array}{l}\text { Female } \\
(n=35)\end{array}$ & $\begin{array}{l}\text { Male } \\
(n=6)\end{array}$ & $\mathrm{P}^{*}$ & $\begin{array}{l}\text { Female } \\
(n=10)\end{array}$ & $\begin{array}{l}\text { Male } \\
(n=3)\end{array}$ & $\mathrm{P}^{*}$ \\
\hline Body mass index $\left(\mathrm{Kg} / \mathrm{m}^{2}\right)$ & $29.75 \pm 5.41$ & $27.12 \pm 4.50$ & 0.203 & $28.22 \pm 4.67$ & $28.77 \pm 5.29$ & 0.606 \\
\hline Body fat (\%) & $38.17 \pm 5.63$ & $28.90 \pm 5.06$ & 0.001 & $36.98 \pm 8.17$ & $30.40 \pm 4.23$ & 0.044 \\
\hline Waist circumference $(\mathrm{cm})$ & $98.46 \pm 10.64$ & $102.16 \pm 13.68$ & 0.858 & $95.90 \pm 16.46$ & $103.27 \pm 7.29$ & 0.155 \\
\hline Fasting blood glucose $(\mathrm{mg} / \mathrm{dL})$ & $92.63 \pm 16.84$ & $85.60 \pm 10.85$ & 0.267 & $94.76 \pm 12.24$ & $98.33 \pm 23.45$ & 0.588 \\
\hline Serum triglyceride $(\mathrm{mg} / \mathrm{dL})$ & $119.15 \pm 54.69$ & $116.00 \pm 44.08$ & 0.881 & $124.23 \pm 70.19$ & $127.66 \pm 114.09$ & 0.928 \\
\hline Serum cholesterol (mg/dL) & $213.42 \pm 49.85$ & $193.16 \pm 27.03$ & 0.799 & $184.50 \pm 27.83$ & $228.33 \pm 32.65$ & 0.589 \\
\hline Serum HDL-c (mg/dL) & $61.06 \pm 12.83$ & $51.83 \pm 12.59$ & 0.833 & $53.60 \pm 13.18$ & $58.66 \pm 6.02$ & 0.766 \\
\hline Serum LDL-c (mg/dL) & $119.74 \pm 34.88$ & $124.76 \pm 28.74$ & 0.708 & $136.56 \pm 54.93$ & $117.04 \pm 46.13$ & 0.515 \\
\hline
\end{tabular}

*Student's t test.

TABLE 3 Classification of cardiovascular risk, according to the Framingham score, by age group and sex of individuals with abdominal obesity seen by a clinical school of nutrition, Maceió (AL), 2009.

\begin{tabular}{|c|c|c|c|c|c|c|c|c|}
\hline \multirow[b]{2}{*}{ Cardiovascular risk } & \multicolumn{4}{|c|}{ Adults ( $<60$ years) } & \multicolumn{4}{|c|}{ Elderly (> 60 years) } \\
\hline & $\begin{array}{l}\text { Female } \\
(n=35)\end{array}$ & $\begin{array}{l}\text { Male } \\
(n=6)\end{array}$ & $\begin{array}{l}\text { Total } \\
(n=41)\end{array}$ & $\mathrm{P}^{*}$ & $\begin{array}{l}\text { Female } \\
(n=10)\end{array}$ & $\begin{array}{l}\text { Male } \\
(n=3)\end{array}$ & $\begin{array}{l}\text { Total } \\
(n=13)\end{array}$ & $\mathbf{p}^{*}$ \\
\hline & n (\%) & $\mathrm{n}(\%)$ & n (\%) & & n (\%) & $\mathrm{n}(\%)$ & $\mathrm{n}(\%)$ & \\
\hline Low & $33(94.28)$ & $5(83.33)$ & $38(92.68)$ & 0.3860 & $9(90.00)$ & $2(66.66)$ & $11(84.61)$ & 0.4230 \\
\hline Medium & $1(2.85)$ & $1(16.66)$ & $2(4.87)$ & 0.2743 & $1(10.00)$ & $1(33.33)$ & $2(15.38)$ & 0.4230 \\
\hline High & $1(2.85)$ & $0(0)$ & $1(2.43)$ & 0.8536 & $0(0)$ & $0(0)$ & $0(0)$ & ----- \\
\hline
\end{tabular}

\section{Discussion}

Obesity, especially located at the abdominal or visceral level, is considered one of the greatest risk factors for coronary artery disease, as well as being associated with increased prevalence of hypertension, dyslipidemia and diabetes, which in turn also contribute to the worsening of ischemic heart disease. ${ }^{15}$ In the present population, all of the individuals studied were people with abdominal obesity, with WC values above that recommended by the IDF. ${ }^{11}$ In addition, despite the studied population not presenting a history of cardiovascular illness or events, the presence of diseases resulting from obesity was observed, such as dyslipidemia, hypertension and DM.

The estimated risk of atherosclerotic disease results from the sum of the risk associated with each of the risk factors plus the escalation caused by synergism between some of these factors. Given the complexity of these interactions, the intuitive attribution of the risk often results in underestimation or overestimation of cases with greater or lesser risk, respectively. To circumvent this difficulty, several algorithms have been created based on regression analyses of population studies, by means of which the identification of the overall risk is improved substan- tially. Among the existing algorithms, the Framingham Risk Score estimates the likelihood of myocardial infarction or death from coronary heart disease within 10 years in individuals with no previous diagnosis of clinical atherosclerosis. ${ }^{8}$

The ability to estimate the absolute risk within ten years allows preventive actions, mainly directed at the population strategy, as well as the search for individuals at high cardiovascular risk. ${ }^{16}$ It should be pointed out that the Framingham score is intended for calculation of risk for individuals without clinical manifestations of cardiovascular disease. ${ }^{17}$

The present study corroborates the study by Cavagioni et al. ${ }^{18}$ whose goal was to determine the prevalence of metabolic syndrome and to identify variables related to professional drivers in transit on the Highway BR-116, where the majority of the individuals had a low cardiovascular risk score. The authors explain this as a higher percentage of individuals in the study population in the age group of 30 to 40 years.

In addition, in study by Sampaio et al. ${ }^{19}$ with patients seen at a family health unit (USF) in Maceió, Alagoas, aimed at estimating the absolute risk of cardiovascular 
disease according to the Framingham score as well as relating to other risk factors, the results showed that 59.05\% of the subjects had a low cardiovascular risk and prevalence of risk factors such as a sedentary lifestyle, dyslipidemia, changes in fasting glucose and high blood pressure. It is important to point out that the majority of individuals were aged between $30-49$ years, and that this is a group attended by a continuous preventive service.

In the present study, this justification cannot be taken into account, since more than half $(71 \%)$ of the subjects studied are in the age group of 40 to 67 years, in addition to the cardiovascular risk not being related with the increase in age. Furthermore, according to the same authors, the use of this score may not identify low-risk individuals in the short term with lifestyles that would predispose them to develop cardiovascular disease in the long term, which would justify further efforts aimed at interventions on the modifiable risk factors for cardiovascular disease.

The results of the present research are related with the study by Rodrigues $\&$ Phillipi, ${ }^{20}$ conducted in southeastern Brazil, where the women involved presented low cardiovascular risk, according to Framingham score, compared to men. When age is taken into account, Sanches et al. ${ }^{15}$ claim that death caused by heart disease is greater in men (39\%) than in women between the ages of 45 and 64 years of age. However, after age 65 , the mortality rate for heart disease in women exceeds that of men by $22 \%$.

In the study conducted by Texeira et al. ${ }^{21}$ aiming to describe food consumption and cardiovascular risk factors present in outpatient patients, it was noted that more than half of the population under study was obese, with $92 \%$ of individuals presenting a high WC, and about $80 \%$ of these individuals classified as high and medium risk of developing cardiovascular disease within 10 years according to the Framingham score. This does not corroborate our research. This fact is explained by the authors as caused by the high consumption of saturated fatty acids, cholesterol, and sodium-rich food, as well as insufficient intake of fruits, vegetables, legumes and fiber; and also the high prevalence of sedentary, diabetic and hypertensive individuals.

According to Barbosa, Scala $\&$ Ferreira ${ }^{22}$ the increasing morbidity and mortality from chronic-degenerative diseases is associated with excess weight, mainly abdominal fat deposits, favoring the occurrence of cardiovascular events, particularly coronary events. In the present research only $4 \%$ of the individuals studied presented a medical diagnosis of DM compared with $23 \%$ for high blood pressure and $28 \%$ for HDL-c below the normal limits.
The waist circumference in this study had a weak correlation with cardiovascular risk, and was not correlated in a study by Casanueva, ${ }^{23}$ which aimed to assess the relevance of abdominal obesity and obesity in the prevalence of CVD, diabetes mellitus, dyslipidemia and hypertension in primary care patients and to verify whether WC should be included in routine clinical practice, in addition to the body mass index. The frequency of CVD increased in parallel with increased adiposity as measured by BMI or WC. Both WC and age were associated with CVD, with each additional centimeter of WC increasing the likelihood of CDV. Abdominal obesity was significantly associated with CVD. Some individuals with abdominal obesity but a slim BMI showed an increased prevalence of cardiovascular disease and diabetes. In addition, abdominal obesity has been strongly associated with dyslipidemia and hypertension. ${ }^{23}$

Unlike that proposed by the WHO, a study by Haun, ${ }^{24}$ that aimed to compare the waist/stature ratio (WHTR) with other anthropometric indicators of obesity in order to point out the high coronary risk (HCR) concluded that WC was not the best predictor of HCR, although it presented better accuracy than BMI for both sexes.

In opposition to this research, in a study by Castro et al. ${ }^{25}$ with obese and overweight individuals aiming to assess the impact of body fat distribution on cardiovascular risk, it was observed that the prevalence of hypertension increased from $35.7 \%$ in those with WHR between 0.73 and 0.88 to $66.6 \%$ in those with WHR $>0.97(\mathrm{p}<0.05)$, regardless of the BMI, and the SBP values were weakly correlated with the WC measurements $(\mathrm{r}=0,35 ; \mathrm{p}<0.0001)$.

Alves, Coutinho $\&$ Sanches, ${ }^{26}$ conducted a study to verify the association between anthropometric indicators and risk of cardiovascular disease in adults treated at the $\mathrm{Mu}$ nicipal Hospital of Esteio, state of Rio Grande do Sul (RS), where there was a greater chance of high cardiovascular risk (HCR) among men with high WHR (OR: 2.98; 95CI 1.22-7.27) and increased conicity index (OR: 6.52; 95CI 1.45-29.33); while among women, there was an association between the HCR an high WHR measurements (OR: 7,05; 95CI 2.38-20.85). Unlike the present research, the inadequacy of the WHR and conicity index were associated with high cardiovascular risk, noting that the anthropometric measurements are easy to execute and can be used to discriminate HCR and enable early nutritional intervention strategies.

It is important to reinforce that the traditional Framingham score was an instrument developed in the 1950s and validated in the $60 \mathrm{~s}$ and $70 \mathrm{~s},{ }^{8}$ a period in which the prevalence of excess weight and obesity in the United 
States was one-third of the current level, and acute myocardial infarction was more frequent in male gender. ${ }^{27}$ Since the 1980s, heart attacks are more common in women and obesity has become a global epidemic. ${ }^{28}$ Therefore, it is possible that this score has underestimated the cardiovascular risk in the current population, and is, therefore, a limitation to the study.

\section{Conclusion}

Abdominal fat distribution was weakly related to cardiovascular risk in patients seen by a clinical school of nutrition.

Despite the low number of individuals at medium or high risk, the risk of developing cardiovascular disease within 10 years increases according to certain factors, such as diabetes, smoking, age, among others. In the present study, this was regardless of age group.

It has become essential to promote interventions, including educational activities about healthy eating and physical activity, since weight reduction in overweight or obese individuals leads to a significant improvement in insulin resistance and consequently a reduction in cardiovascular risk factors.

\section{ACKNOWLEDGMents}

Nutritionists Andréa Santana dos Santos, Ana Luiza Tenório Guimarães, Fabiana Grace Araújo da Silva and Vanessa Fernanda Baia Cardoso for their contributions in data collection.

\section{Resumo}

Avaliação do risco cardiovascular segundo escore de Framingham e obesidade abdominal em indivíduos atendidos por uma clínica escola de nutrição

Objetivo: avaliar a relação entre a distribuição central de gordura e o risco cardiovascular em indivíduos atendidos por uma clínica escola de nutrição, classificando-os pelo escore de Framingham.

Método: estudo do tipo transversal, realizado em uma clínica escola de nutrição de uma faculdade particular da cidade de Maceió, Alagoas. Foram selecionados aleatoriamente indivíduos adultos e idosos portadores de obesidade abdominal, de ambos os sexos, atendidos no período de agosto a dezembro de 2009, sem histórico de miocardiopatias e eventos cardiovasculares. Para determinação do risco cardiovascular, foi calculado o escore de Framingham. Todas as análises foram realizadas com o auxílio do programa SPSS versão 20.0, considerando $\mathrm{p}<0,05$ como significativo.
Resultados: foram estudados 54 indivíduos, sendo 83\% do sexo feminino, com idade média de 48 anos, variando de 31 a 73 anos. Foi observada correlação praticamente nula entre as medidas de circunferência da cintura e o risco cardiovascular dos indivíduos estudados $(\mathrm{r}=0,065$; $\mathrm{p}=0,048)$, não havendo relação entre esses parâmetros.

Conclusão: a distribuição central de gordura se relacionou fracamente com o risco cardiovascular em indivíduos atendidos por uma clínica escola de nutrição.

Palavras-chave: obesidade abdominal, doenças cardiovasculares, obesidade, fatores de risco.

\section{RefEREnCES}

1. Mansur AP, Favarato D. Mortalidade por doenças cardiovasculares no Brasil e na Região Metropolitana de São Paulo: Atualização 2011. Arq Bras Cardiol. 2012; 99(2):755-61.

2. Graves BW. The obesity epidemic: scope of the problem and management strategies. J Midwifery Womens Health. 2010; 55(6):568-78.

3. Catenacci VA, Hill JO, Wyatt HR. The obesity epidemic. Clin Chest Med. 2009; 30(3):415-44

4. Harwood HJ Jr. The adipocyte as an endocrine organ in the regulation of metabolic homeostasis. Neurophamacology. 2012; 63(1):57-75.

5. Oliveira CN, Costa RG, Ribeiro RL. Obesidade abdominal associada a fatores de risco a saúde em adultos. Saúde \& Ambiente em Revista. 2008; 3(1):34-43.

6. Ponte LMB. Composição corporal e insulino-resistência. [Dissertation]. Porto: Faculdade de Ciências Sociais, Universidade Fernando Pessoa, 2011. Available from: http://bdigital.ufp.pt/bitstream/10284/2481/1/T_15226.pdf.

7. Lavie CJ, Milani RV, Artham SM, Patel DA, Ventura HO. The obesity parodox, weight loss, and coronary disease. Am J Med. 2009; 122(12):1106-14.

8. Kannel WB, McGee D, Gordon T. A general cardiovascular risk profile: the Framingham Study. Am J Cardiol. 1976; 38(1):46-51.

9. World Health Organization (WHO). Physical status: the use and interpretation of anthropometry. Geneva: WHO, 1995. N.452.

10. International Diabetes Federation: IDF, 2006 [cited 2012 May]. Available from: http://www.idf.org/metabolic-syndrome/faqs.

11. Wilson PWF, Ralph BDA, Levy D, Belanger AM, Silbershatz H, Kannel WB. Prediction of coronary heath disease using risk factor categories. Circulation. 1998; 97(18): 1837-47.

12. V Diretriz Brasileira de Dislipidemias e Prevenção da Aterosclerose. Sociedade Brasileira de Cardiologia. Arq Bras Cardiol. 2013; 101(4 Supl 1). Available from: http://publicacoes.cardiol.br/consenso/2013/V_Diretriz_Brasileira de_Dislipidemias.pdf.

13. Diretriz da Sociedade Brasileira de Diabetes. Sociedade Brasileira de Diabetes. 2012-2013.

14. VI Diretriz Brasileira de Hipertensão Arterial. Arq Bras Cardiol. 2010; 95(1):1-51

15. Koopman RJ, Swofford SJ, Beard MN, Meadows SE. Obesity and metabolic disease. Primary care. Clin Office Pract. 2009; 36(2):257-70.

16. Lotufo PA. O escore de risco de Framingham para doenças cardiovasculares. Rev Med. 2008; 87(4):232-7.

17. Gowdak LHW, Paula FJ, Giorgi DMA, Vieira MLC, Krieger EM, De Lima JJG. Doença cardiovascular e fatores de risco cardiovascular em candidatos a transplante renal. Arq Bras Cardiol. 2005; 84(2):156-60.

18. Cavagioni LC, Beseñor IM, Halpern A, Pierin AMG. Síndrome metabólica em motoristas profissionais de transporte de cargas da rodovia BR-116 no trecho Paulista-Régis Bittencourt. Arq Bras Endocrinol Metab. 2008; 52(6):1015-23

19. Sampaio MR, Melo MBO, Wanderley MAS. Estratificação do risco cardiovascular global em pacientes atendidos numa unidade de saúde da família (USF) de Maceió, Alagoas. Rev Bras Cardiol. 2010; 23(1):47-56.

20. Rodrigues TFF, Phillipi ST. Avaliação nutricional e risco cardiovascular em executivos submetidos a check-up. Rev Assoc Med Bras. 2008; 54(4):322-7.

21. Teixeira AMNC, Sachs A, Santos GMS, Asakura L, Coelho LC, Silva CVD Identificação de risco cardiovascular em pacientes atendidos em ambulatório de nutrição. Rev Bras Cardiol. 2010; 23(2):116-23. 
22. Barbosa LS, Scala LCN, Ferreira MG. Associação entre marcadores antropométricos de adiposidade corporal e hipertensão arterial na população adulta de Cuiabá, Mato Grosso. Rev Bras Epidemiol. 2009; 12(2):237-47.

23. Casanueva FF, Moreno B, Azeredo RR, Massien C, Conthe P. Relationship of abdominal obesity with cardiovascular disease, diabetes and hyperlipidaemia in Spain. Clin Endocrinol (Oxf). 2010; 73(1):35-40.

24. Haun DR, Pitanga FJG, Lessa I. Razão cintura/estatura comparado a outros indicadores antropométricos de obesidade como preditor de risco coronariano elevado. Rev Assoc Med Bras. 2009; 55(6):705-11.
25. Carneiro G, Faria NA, Ribeiro Filho FF, Guimarães A, Lerário D, Ferreira SRG, et al. Influência da distribuição da gordura corporal sobre a prevalência de hipertensão arterial e outros fatores de risco cardiovascular em indivíduos obesos. Rev Assoc Med Bras. 2003; 49(3):306-11.

26. Alves LR, Coutinho V, Santos LC. Indicadores antropométricos associados ao risco de doença cardiovascular. Arq Sanny Pesq Saúde. 2008; 1(1):1-7.

27. Mitchell S, Shaw D. The worldwide epidemic of obesity. Best Pract Res Clin Obstet Gynaecol. 2015; 29(3):289-99.

28. Davidson PM, Mitchell JA, DiGiacomo M, Inglis SC, Newton PJ, Harman J, et al. Cardiovascular disease in women: Implications for improving health outcome. Collegian. 2012; 19(1):5-13. 